\title{
Data Access and Research Transparency (DA-RT): A Joint Statement by Political Science Journal Editors
}
7 ransparency requires making visible both the empirical foundation and the logic of inquiry of research. We agree that by January 15, 2016 we will:

- Require authors to ensure that cited data are available at the time of publication through a trusted digital repository. Journals may specify which trusted digital repository shall be used (for example if they have their own dataverse). If cited data are restricted (e.g., classified, require confidentiality protections, were obtained under a non-disclosure agreement, or have inherent logistical constraints), authors must notify the editor at the time of submission. The editor shall have full discretion to follow their journal's policy on restricted data, including declining to review the manuscript or granting an exemption with or without conditions. The editor shall inform the author of that decision prior to review.

- Require authors to delineate clearly the analytic procedures upon which their published claims rely, and where possible to provide access to all relevant analytic materials. If such materials are not published with the article, they must be shared to the greatest extent possible through institutions with demonstrated capacity to provide long-term access.

- Maintain a consistent data citation policy to increase the credit that data creators and suppliers receive for their work. These policies include using data citation practices that identify a dataset's author(s), title, date, version, and a persistent identifier. In sum, we will require authors who base their claims on data created by others to reference and cite those data as an intellectual product of value.

- Ensure that journal style guides, codes of ethics, publication manuals, and other forms of guidance are updated and expanded to include improved data access and research transparency requirements.

- American Journal of Political Science

- American Political Science Review

- British Journal of Political Science

- Comparative Political Studies

- Conflict Management and Peace Science

- Cooperation and Conflict

- European Journal of Political Research

- European Political Science

- European Union Politics

- International Interactions

- International Security

- Journal of Conflict Resolution

- Journal of European Public Policy
- Journal of Peace Research

- Journal of Theoretical Politics

- Quarterly Journal of Political Science

- Party Politics

- Political Analysis

- Political Behavior

- Political Science Research and Methods

- Research and Politics

- Rivista Italiana di Scienza Politica

- State Politics and Policy Quarterly

- Security Studies

- The Journal of Politics

- The Political Methodologist 